\title{
VIAJANDO NÃO, SÓ SONHANDO!
}

\author{
Patrícia Cavalcanti Schmid ${ }^{\star}$
}

\begin{abstract}
RESUMO
O artigo traz um relato de caso, com discussão teórica, abordando o percurso de um jovem psicótico através de um Centro de Reabilitação Psicossocial (Centro de Atenção Psicossocial Infanto-Juvenil - CAPSIJ/CARIM/IPUB/UFRJ). O jovem tem história de longa institucionalização psiquiátrica, após a qual começou um outro tratamento oferecido pelo Centro e caracterizado por uma proposta de atenção diária. São apresentados momentos desse trabalho e as falas do jovem, sempre com uma articulação teórica, feita a partir de referenciais psicanalíticos, filosóficos e de psicoterapia institucional. Estes momentos ilustram a riqueza de seu quadro, demonstrando que a longa institucionalização do jovem foi, absolutamente, desnecessária.
\end{abstract}

Palavras-chave: Reabilitação psicossocial. Saúde mental infanto-juvenil. Psicose e adolescência.

\section{I'M JUST DREAMING}

\begin{abstract}
This article presents the trajectory of a psychotic adolescent in a Psychosocial Rehabilitation Service (CAPSIJ / CARIM / IPUB / UFRJ). He lived for a long time in a Mental Health Institution and, after this period he initiated a new treatment in the CAPSIJ. This treatment proposed a daily care and in the article some important moments of his trajectory are presented and discussed through psychoanalytic and philosophical aspects and through institutional psychotherapy ideas. These moments presented show the importance and the beauty of his trajectory and also emphasize how the long time he passed in a Mental Health Institution was completely unnecessary .
\end{abstract}

Keywords: Psychosocial rehabilitation. Children and adolescents Mental health. Psychosis and adolescence.

\footnotetext{
* Psiquiatra, especializada na área infanto-juvenil, diretora do Serviço Infanto-Juvenil do Instituto Municipal Nise da Silveira e mestranda de Saúde Mental do IPUB//UFRJ.

E-mail: patschmid@predialnet.com.br
} 


\section{A tarjetória de UM AdOLESCENTE nUm CENTRo de REABILITAÇÃO PSICOSOCIAL (RPS)}

Lembrando Saraceno (1996) quando afirma ser o campo da Reabilitação Psicossocial (RPS) uma prática em busca de teoria, apresentamos este trabalho como uma tentativa de teorizar sobre a prática, no sentido de participar dessa busca teórica em nosso campo.

Quando dizemos RPS, concebemos uma nova forma de abordagem sobre o sofrimento psíquico. Falamos de uma outra clínica, de uma clínica de convívio, de um estar com o sujeito portador de transtornos psiquiátricos. Falamos de um cotidiano que se partilha, de almoçar junto, de realizar passeios, de ouvir histórias nos consultórios, mas também, nos corredores, na rua, nos espaços comuns de informalidade. Falamos sobre um dividir cuidados com as famílias, de uma nãoperda de vínculos sociais, falamos de um trabalho de inserção e vida social. Defendemos uma clínica plural, que se utiliza de vários recursos e saberes, construindo seu caminho ao caminhar, lado a lado com quem sofre de um transtorno psiquiátrico. Para denominar nosso trabalho, podemos dizer que falamos de uma clínica de percursos. Este artigo se propõe a relatar um destes percursos. Neste relato entrecruzar-se-ão, a todo momento, prática e reflexões teóricas, na tentativa de responder ao chamado de Saraceno.

O percurso que descreveremos agora está sendo feito com Denis, um adolescente de 15 anos, que freqüenta o Centro de Atenção Psicossocial Infanto-Juvenil do Instituto de Psiquiatria da Universidade Federal do Rio de Janeiro (CAPSIJ). Denis, pela riqueza de seu percurso e gravidade de sua história, tornou imperativa a existência deste relato.

\section{O PERCURSO ANTERIOR}

O encaminhamento de Denis ao Serviço foi realizado pela justiça, na figura de um conceituado juiz da Vara da Infância e Adolescência do Rio de Janeiro. Este, durante visita que realiza, habitualmente, às entidades que atendem jovens, encontrou Denis que já estava há um ano internado. Diante desta estada tão prolongada, determinou de imediato sua alta e nos consultou sobre a possibilidade de seu atendimento em nosso Centro.

Antes desta internação de um ano, Denis havia passado por cerca duas a três internações em outro hospital psiquiátrico. Antes destes fatos, Denis, quando criança aos cinco e nove anos, teve alguns atendimentos ambulatoriais individuais, mas sem regularidade. Segundo relato dos pais, sempre foi uma criança agitada, irritadiça, chegando a ser diagnosticada como hiperativa. Só conseguiu estudar até a quarta série, tendo repetido várias séries até chegar a este nível. Ao entrar na adolescência, passou a ficar mais agitado, começando a falar coisas estranhas, a se comportar de forma diferente, fez uso de drogas e começou a ficar agressivo. A partir daí, a internação psiquiátrica surgiu como alternativa para a família, que já não suportava o quadro de Denis. 


\section{O percurso no Centro - Histórias e Reflexões: A CHEgada}

A história de Denis nos impressionou antes mesmo de conhecê-lo. Fomos informados pelo juiz de seu longo período internado e, de imediato, nos veio a reflexão de como o dispositivo manicomial é também muito forte na realidade da juventude e infância no Brasil, embora se tenda a não reconhecer essa realidade. Outras idéias, ainda, nos vieram à mente. O que teria levado esses pais a permitirem tão longo tempo de exclusão? Quais seriam os sintomas de Denis? Seriam tão graves que pudessem justificar tão longo internamento? Como seria atendê-lo e propor a ele uma nova abordagem, estando por tanto tempo sem um cuidado eficaz? Desafios sem dúvida, mas uma clínica como esta não se faz sem desafios e, prontamente, nos dispusemos a enfrentá-lo.

Conhecemos Denis no dia seguinte ao do contato com o juiz. Ele veio com seus pais. Apresentava um ar austero e idéias de grandeza, dizendo-se muito rico e dono de vários apartamentos. Negava que estivesse saindo de alta de uma internação e relatava que esteve descansando e viajando, mentalmente, para outros países como o Havaí. Mostrava-se agitado, arredio e sem crítica de alguma problemática. Dizia que seus pais não eram aqueles e sim o Presidente dos Estados Unidos e uma apresentadora da televisão, loura de olhos azuis (a Xuxa) - Denis é negro.

Os pais relataram um pouco da história deles com Denis e mostravam discordância com a atitude do juiz. Os pais são separados e sentiam-se incapazes de cuidar de Denis naquele momento. Conversamos longamente com Denis e os pais, refizemos o esquema medicamentoso e remarcamos o atendimento para o mais breve possível. No segundo atendimento marcado, os pais compareceram sem Denis. Ele havia sido internado novamente. Os pais relataram que, na rua enquanto voltavam para casa, ele não aceitou as ordens dos pais, acabando por ficar muito agressivo, envolvendo a polícia na situação, o que acabou culminando em nova internação psiquiátrica.

Parecia-nos que, até aquele momento, a internação se mostrava como a única possibilidade de cuidado para Denis, nenhuma outra abordagem parecia eficaz ou outras alternativas não eram pensadas. E o mais grave, não só pelos familiares, mas também pelo próprio sistema de saúde: buscava-se o caminho certamente mais rápido de intervenção, porém pobre e lento, muito lento em possibilidades para o sujeito. Isto nos lembrou a atualidade de Foucault ao questionar o sentido da internação: "daí a supor que o sentido do internamento se esgota numa obscura finalidade social que permite ao grupo eliminar os elementos que lhe são heterogêneos ou nocivos" (FOUCAULT, 1993, p. 112). Parecia-nos imperativo intervir no sentido de romper este ciclo, muito sério para um jovem de apenas 15 anos.

Decidimos iniciar de imediato um trabalho terapêutico com os pais, que seriam atendidos pela equipe do Centro. Paralelamente, a equipe também acompanharia Denis na internação, visitando-o semanalmente, construindo algum vínculo com ele até sua alta e vinda regular ao Serviço. 


\section{O PERCURSO NO DIA-A-DIA}

As visitas foram realizadas toda semana pela mesma terapeuta da equipe. A alta de Denis foi acordada e seu encaminhamento foi feito para o CAPSIJ. Denis chegou no início da manhã. Veio com seu pai e aceitou ficar conosco. Logo antes da saída de seu pai, ele queria fumar cigarros. Nosso primeiro problema apareceu. No espaço do CAPSIJ, não é permitido fumar. Denis conversou com a terapeuta com quem já tinha alguma referência, a mesma que o acompanhou nas primeiras consultas e durante a internação. Aceitou sua ponderação, mas mesmo assim tentou pegar cigarros de seu pai, que se irritou, e os dois acabaram por se agredir. Contornamos a situação, Denis ficou conosco e seu pai foi para o grupo terapêutico de família.

Os primeiros dias dele no Centro foram de busca de isolamento; não queria estar nas atividades coletivas, o que era respeitado. Aceitava, por vezes, travar diálogos rápidos com os membros da equipe. Contava ser filho do presidente americano e de uma famosa apresentadora de televisão. Dizia ter viajado para vários países: Austrália, Havaí, Romênia, Estados Unidos. Relatava falar australiano e murmurava algo ininteligível para nós, o que dizia ser australiano. Ao escrever, dizia também que escrevia num inglês australiano, o qual só ele sabia como era. Estas falas eram endereçadas a várias pessoas, em vários momentos. Percebíamos que Denis tecia, ao longo dos dias no CAPSIJ e com as várias pessoas da equipe, seu discurso delirante, muitas vezes só associado por nós nas reuniões de equipe ou em conversas informais. Ao estarmos abertos a receber e a escutar atentamente os fragmentos de seu discurso, podíamos sentir que, pouco a pouco, conquistávamos uma aproximação maior com Denis. Entendíamos, assim, que esta escuta especial acerca de seus relatos delirantes respeitava o grão de verdade que Freud (1986, p. 67) localiza no discurso do psicótico:

Se o enfermo crê com tanta firmeza em seu delírio, isso não se produz por um transtorno (Verkehrung) da sua capacidade de julgar nem se deve ao que há de errôneo em seu delírio. Antes ao contrário, em todo delírio se esconde um grão de verdade; há algo que realmente merece crença e é essa a fonte da conviç̧ão do enfermo, que, portanto está justificada nessa medida.

Notamos, mais à frente, comportamentos com os quais ele começava a nos desafiar e desrespeitar as regras, tais como sair sem avisar, fumar nas salas. Compreendíamos que era um chamado seu ao nosso olhar. Ele sempre tentava se certificar de que estávamos atentos, que tínhamos um olhar significativo sobre ele. Quando percebia que notávamos e o chamávamos ao compromisso com as regras, Denis respeitava e sorria. Parecia regozijante por ter sido olhado. Uma reflexão pôde ser feita sobre estas situações. Na história de Denis e seus pais, em especial com sua mãe, sempre houve uma grande dificuldade de se estar com ele. Sua mãe dizia não saber lidar com um bebê, que ele sempre foi muito agitado, que trabalhava fora e que preferia que a avó materna cuidasse dele, a qual, também, sempre o considerou uma criança difícil. O pai era considerado muito ausente e não partici- 
pava dos cuidados com o menino. Se pensarmos em Lacan (1986) quando diz que o eu se constitui a partir do outro (e do Outro, considerando a vertente imaginária e simbólica da constituição do sujeito), do qual o eu, no início, é puro reflexo, vemos que sobre Denis não chegou a pousar um olhar subjetivante. Para conseguir as melhores condições de constituir-se enquanto sujeito, a criança necessita de um desejo particularizado sobre ela: um olhar que a marque como de certa forma especial para o Outro, alguém desejante que sirva de espelho para sua constituição enquanto um corpo capaz de abrigar um sujeito de desejo. Podemos, então, pensar que o significante mais marcante na construção subjetiva de Denis foi o de criança problema, alguém de difícil relação, fora do campo desejante do Outro. Portanto, acreditamos que nosso sucesso em conseguir ficar com Denis no Centro aconteceu por dois aspectos: primeiro, por termos uma escuta singular e atenta e, segundo, ao construirmos um olhar que de alguma forma o especificou, o particularizou. Desta forma se instaurou o vínculo, a transferência. Isto se evidenciou no discurso delirante de Denis, quando, em diálogo com uma terapeuta, ele lhe disse que havia viajado para o Havaí e lá teria visitado um CAPS em que as pessoas fizeram entrevistas com ele. Logo após, pôde contar que teria passado o fim de semana na Romênia, onde havia visto filmes em vídeo que só passavam lá e dos quais havia sido o produtor. Os filmes se intitulavam: "Preparado para destruir a instituição" e "Louco por ..." e fala o nome da terapeuta

Ressaltamos que este caminho estava sendo feito com Denis nos espaços não formais do Centro. A esta altura ele ainda não conseguia realizar as atividades coletivas, os passeios com o grupo ou tampouco aceitava uma abordagem individual por muito tempo. Isto sempre era respeitado pela equipe. Com o passar dos dias, pudemos notar que Denis começou a aceitar ficar mais nas atividades; já se sentava com os outros, travava algumas conversas, muito embora ainda mantivesse um discurso fortemente delirante e, às vezes, de difícil compreensão para os demais adolescentes. Porém, sua participação nas atividades foi evoluindo, pouco a pouco, com avanços e retrocessos. Ao longo deste trajeto, pudemos perceber em Denis que ele se tornava curioso e assustado com as falas dos demais adolescentes e as nossas sobre seu discurso delirante. Quando era contrariado ou quando sua idéia não era aceita de imediato, se zangava, virava o olhar e andava em círculos falando sozinho pelo Centro, em franca atitude alucinatória. Denis dizia ser louro de olho azul, que não era Denis e sim outra pessoa e o comportamento descrito muitas vezes acontecia quando lhe era dito que entendíamos que podia pensar daquela forma, mas que, para nós, ele era Denis e negro. Por vezes referia ter uma tatuagem em seu braço e o comportamento se repetia ante a recusa de qualquer pessoa em aceitar estar vendo a tatuagem. Denis começou, a partir destes eventos, a apresentar em seu discurso um novo conteúdo, dizendo que todos que não partilhavam de suas idéias eram bonecos, andróides e não eram humanos. Seres feitos por uma poderosa técnica da engenharia. Isto se manteve em sua fala por longo período, classificava-nos a todos como bonecos, os terapeutas e seus pais. Dizia que só ele não era boneco, mas que um Denis, filho dos pais que se diziam seus pais, esse também era um boneco que estava ocupando o seu lugar. Relatava que o verdadeiro Denis ainda iria chegar e que, na realidade, havia outros Denis, todos bonecos. Isto nos lembrou Freud (1969) quando mostra, no caso de Schreber, a 
grandeza indescritível deste diante da certeza de uma catástrofe iminente, o fim do mundo, sendo ele próprio "o único homem real deixado vivo" (FREUD, 1969, p. 92) e as poucas formas humanas que ainda via - o médico, os assistentes, os outros pacientes - apenas "homens apressadamente improvisados" (FREUD, 1969, p. 92). Freud afirma que, desta forma, em seu delírio Schreber mantinha seu eu e o mundo, este sim, era sacrificado. Numa analogia, podemos pensar que as dúvidas impostas pelo outro provocavam algum abalo às certezas delirantes de Denis, para mantê-las era imperativo desqualificar e destruir o valor humano do mundo, todos viraram bonecos, inumanos, mantendo-se apenas ele, fonte de toda verdade humana sobre si mesmo.

Sabíamos que nosso percurso com Denis estava sendo sustentar sua produção delirante, mas estabelecendo um diálogo com ela. Esta idéia nos levou a outras reflexões. Compreendendo o advento da psicose de acordo com Lacan, a psicose emerge de um acidente no registro do significante fundamental: o "Nomedo-pai", que está foracluído. Um acidente que deixa o sujeito à deriva, sem uma amarragem central, sem um ponto de referência. Trata-se da foraclusão de uma função, a função paterna, que não foi constituída. Quando o "Nome-do-Pai" é invocado, chamado em oposição simbólica ao Sujeito, vem à luz esse buraco na cadeia significante, esse furo na possibilidade de dar significado, que só o surgimento da metáfora delirante vai permitir equacionar. Nesse momento podemos assistir à predominância de uma resposta do que Lacan chama de Real, um conceito que é difícil de apreender, mas que numa primeira aproximação deve ser diferenciado de realidade. Neusa Souza $(1999$, p. 47) em sua descrição do Real lacaniano assinala que:

O real é obstáculo, resistência e impasse. Irredutível à lógica, impassível às seduções e metamorfoses do imaginário, barreira inominável ao simbólico e à mobilidade que lhe é própria [...] Do real, portanto, não se pode esperar um mundo. Bem, ao contrário, "por ser ausência radical de sentido" abre a possibilidade de submergir, o que o princípio de realidade constrói, como mundo exterior.

O real, portanto, tem sempre a direção de suplantar o sujeito, mortificá-lo, sendo esta a sua completa vitória. Quando falamos, então, de sustentar o delírio de Denis, podemos pensar na constituição de um discurso que restabeleça o circuito da fala para o sujeito, mas, ao mesmo tempo, remeta à incompletude do Outro, promovendo a dúvida, buscando um furo no real, algo que instaure a chance de manter vivo o sujeito enquanto falante e permitindo-lhe, também, estar mais ligado à realidade e ao universo social. Não falamos de remissão sintomatológica, estrito senso, pois ao delírio cabe um importante papel reorganizador do sujeito, uma tentativa de reestruturação, como nos fala Freud. Falamos, sim, de algo que construa outras possibilidades estruturantes, além do delírio, com as quais este possa se articular, negociar, estabelecendo uma chance de existência mais plural para Denis. Um caminho lento e árduo, mas que deve ser trilhado para abrir outras perspectivas para o sujeito que não só o aprisionamento psicótico. Como fala, ainda, Neuza Souza (1999, p. 55): 
O impossível da voz se atualiza na psicose não raro sob a forma de mandamentos impossíveis - é a alucinação verbal, voz do Outro que se faz ouvir e que brada ditames a um só tempo impossíveis de desobedecer e, permanecendo vivo o sujeito, impossíveis de cumprir.

Desejávamos, portanto, construir com Denis a manutenção de sua condição de sujeito, sujeito desejante, ampliando, assim, a sua rede de possibilidades, no intuito de ajudá-lo a avançar no que lhe fosse possível em sua vida social. Denis aceitava este apoio e partilhava conosco, cada vez mais, suas questões. Sabíamos, porém, que a dúvida vinda do outro era para ele angustiante, respeitávamos o seu limite e o seu tempo, respondendo às suas demandas e não nos antecipando a elas. Nessa época, iniciou-se no Centro, uma oficina de capoeira, realizada por um mestre capoeirista. Este fato deflagrou mudanças importantes no percurso de Denis, que se mostrou muito arredio à atividade. Trancava-se numa das salas e colocava o rádio muito alto. Recusava-se a ouvir ou, ao menos, observar de longe a atividade. Notávamos que a questão do significante negro presente na história da capoeira e nos ritmos tocados assustavam Denis e o atingiam em suas questões. Ele mesmo falou quando questionado sobre o porquê de não querer participar: "é muito afro para mim". Aceitávamos a resistência de Denis e estas atitudes dele nos impuseram novas tentativas de elaboração e compreensão teórica. Na família de Denis havia uma forte questão racial, de dificuldade com a aceitação do fato de seu pai, mulato, haver se casado com uma mulher negra. Isto nos remeteu, novamente, a Neusa Souza em seu outro estudo sobre a identidade negra quando fala de como:

O negro [...] é aquele cujo o Ideal do Ego é branco [...] aquele que nasce e sobrevive imerso numa ideologia que lhe é imposta pelo branco como ideal a ser atingido [...] Na construção de um Ideal de Ego branco a primeira regra básica que ao negro se impõe é a negação, o expurgo de qualquer mancha negra (SOUZA, 1983, p. 23-25)

Podemos pensar que Denis portava em si as marcas psíquicas destas questões histórico-culturais, mas não suficientemente inscritas num registro simbólico a ponto de determinar a estruturação de um Ideal do Eu, como o que seria pensável numa estrutura neurótica. Como estamos diante do advento do fenômeno da psicose, podemos discutir que estas questões retornam, assim, no campo do Real. Denis apresenta-se, indiscutivelmente, branco e a resistência à capoeira era sua maneira de expurgar a possibilidade de ter acesso à questão negra, continuando desta forma delirantemente branco, louro e de olhos azuis. O lugar desse gêmeo do eu marcado pela questão do ideal do eu branco parece ser o que Lacan (1981) aponta, quando discute que, na economia psíquica, o eu não está nunca só, mas sempre acompanhado por um gêmeo prenhe de delírio, o "eu-ideal". O processo de desencadeamento da psicose consistiria em fazer falar a esse gêmeo delirante, que se transforma num personagem, que comanda, comenta ou faz eco aos pensamentos do sujeito. 
Porém, como continuaremos a discutir, apesar de tudo, havia uma curiosidade latente em Denis, a qual era percebida pela equipe e estimulada; ele gostava de ouvir falar da capoeira e o víamos conversar sobre o assunto com os outros adolescentes. Por meio de um trabalho gradual, ele foi se tornando menos arredio e já se permitia observar por alguns minutos a oficina. O mestre capoeirista interessou-se por ele e tentava sempre se aproximar do mesmo e, em sendo também negro, buscava falar-lhe sobre a sua raça e sua história.

Ao longo deste processo, em sua produção delirante já pudemos vê-lo trazer a questão negra. Denis gostava muito de um mapa-múndi que há no Centro, sobre ele parava por longos períodos e falava das várias viagens que já tinha realizado pelo mundo, inventando países, continentes. Nas primeiras vezes que nos trouxe estas questões, sempre falava de países europeus, de locais nos Estados Unidos, de pessoas brancas, mesmo naqueles países criados em seu delírio. Com o tempo, ouvimos Denis falar que viveu cinco anos na África e que gostou de conhecer aquele país. Num outro diálogo, no qual de novo dizia ser branco, dirigiu-se ao espelho e perguntou a um outro adolescente e ao terapeuta que estava com eles se o viam branco de olhos azuis. Diante da resposta negativa, disse que naquele espelho, às vezes, também já se via negro, mas é que o espelho era muito velho. Já na casa de seu pai, onde o espelho era novo, se via sempre branco de olhos azuis. Isto nos sinalizava que seu percurso pelo Centro estava the possibilitando ver-se, ainda que de forma incipiente, especularmente, como negro. O que não era, ainda, cabível no circuito familiar.

Nossa trajetória com Denis continuava e este, a cada dia, mostrava-se mais curioso sobre a capoeira. Ele começou a se aproximar mais naturalmente do mestre e a olhar os demais adolescentes jogando por mais tempo. Já não se trancava na sala, deixava a porta entreaberta. Em seu discurso vimos que ele, que por vezes falava de vários Denis, começou a relatar que o Denis negro estava para chegar e, aí sim, ele poderia ir embora para seu apartamento em outro país. Num diálogo com uma terapeuta, esta lhe disse que entendia que houvesse vários Denis, mas que acreditava que um dia ele poderia se sentir mais unido. Que estava ali para ajudá-lo. Denis se aproximou dela muito afetivamente e lhe disse: "eu entendo que seu trabalho como psiquiatra é ir limpando, limpando até ficar um Denis só. Mas não sei se eu quero o Denis negro". Porém, havia uma dúvida neste não querer, pois ele continuava muito interessado na atividade de capoeira e já aceitava tocar o pandeiro.

Notamos, também, que, a esta altura, ele já não apresentava os comportamentos de intensa ansiedade, andando e falando sozinho como antes. Sua atividade alucinatória no Centro, muita embora ainda houvesse, era de intensidade cada vez menor. Já o percebíamos com um discurso mais na realidade, mais coerente e interativo. Este processo acompanhou a evolução de sua participação na oficina de capoeira. A certa altura, Denis não só já aceitava tocar o pandeiro, como se interessou pelo berimbau e começou a se mexer ao som dos ritmos. Até que um dia, inesperadamente, pudemos nos surpreender com Denis aceitando jogar capoeira com o mestre. Aquele momento, acreditamos, testemunhava a relação mais positiva de Denis com as marcas do Outro inscritas nele. Testemunhava uma possível amarração de elementos reais, simbólicos e imaginários, 
estruturando em Denis uma identidade corporal em que o real do corpo negro encontrava sua imagem reconhecida pela chancela do simbólico. Para ratificar estas idéias, logo nos dias seguintes, durante uma oficina terapêutica que trabalha com a palavra, Denis num debate sobre racismo discutiu a questão, falou contra o preconceito, abordou a abolição da escravatura. Disse, de maneira muito peculiar, que "Zumbi ajudou Princesa Isabel" a libertar os escravos e que racismo é crime, comparando racismo e nazismo. Denis defendia a si mesmo e sua identidade, com um vigor que nunca havíamos visto antes. Estes acontecimentos nos fizeram acreditar que estávamos tendo êxito em construir as tão almejadas outras possibilidades estruturantes para e com ele. Todo este caminho, até aqui trilhado com Denis, nos remeteu à Jairo Goldberg (1996, p. 68), quando discute, a partir da análise de Oury que:

Um outro aspecto a caracterizar a Clínica é a importância da vida cotidiana, do ambiente, que fornecem uma matéria permeável propícia ao estabelecimento de uma rede de relações de sociabilidade da qual emerge a instância terapêutica. A meta da psicoterapia institucional é criar um coletivo orientado de tal forma que tudo seja ativado (terapêuticas biológicas, analíticas, desobstrução dos sistemas alienantes sócioeconômicos etc.) para que o psicótico alcance um campo onde ele possa se balizar, redelimitar seu corpo numa dialética entre parte e totalidade, participar do corpo institucional pela mediação dos objetos transicionais... Esses objetos são os ateliês, reuniões, lugares privilegiados, funções, como a participação nos sistemas concretos de gestão ou organização.

Ao circular pelo corpo institucional caracterizado pelo Centro, Denis pôde ir se redelimitando, alcançando algumas amarras, a partir da mediação exercida pelo espaço na figura dos terapeutas e das oficinas. Vários dispositivos foram acionados para acolhê-lo e sustentar seu trajeto, facilitando alguma estruturação identificatória, o que, acreditamos, se mostrou neste seu processo de tornar-se negro.

Assim, ao longo dessa intensa etapa de seu percurso, já vemos Denis como um jovem bem humorado e muito afetivo. Sua relação familiar está mais tranqüila, embora seus pais ainda necessitem, como ele, de um intenso trabalho terapêutico. Sabemos que se há algum sucesso na trajetória com Denis, este se deve também, em muito, ao trabalho paralelo de terapia com seus pais. Num último atendimento individual, antes da elaboração deste artigo, pudemos ter outras surpresas com ele. Neste, Denis conseguiu dizer que sabia que tinha problemas psiquiátricos, que falava sozinho. Dizia ter "lembranças" que o incomodam muito. Falou de masturbação e de dúvidas sobre a sexualidade. Disse que é o Denis e negro, mas que ainda acha que existe outro Denis que tem muitos problemas, mas que está melhorando. Perguntou à terapeuta se ela também sofria com lembranças. Falou de suas vivências alucinatórias, das coisas que via e aceitou discutir como lidar com elas. 
Referiu-se a si mesmo como um "cara legal" que toma o remédio porque quer melhorar. Pediu que o ajudássemos a voltar a estudar, com muita intensidade, dizendo que já perdeu muito tempo. Pela primeira vez, vimos em seu discurso um distanciamento de seus sintomas, tendo ele alguma crítica sobre os mesmos. Partilhou, neste atendimento, com muita clareza o sofrimento das vivências alucinatórias, aceitando isto como algo que ele pode cuidar e melhorar. Falou de resgatar laços sociais, ao pedir ajuda para voltar a estudar. Denis terminou esta sessão abraçando a terapeuta.

Neste exato momento, a sensação que se produziu é a de que o percurso devia continuar, mas que se sinalizava, com certeza, o fortalecimento de sua condição de sujeito e que se abriam, assim, os caminhos para a ampliação de suas potencialidades dentro do corpo social. Tínhamos claro que estávamos conseguindo sustentá-lo em seu processo e que sua estada longa num hospício tinha sido completamente insensata e conseqüência de um sistema nefasto que impede que o sujeito seja efetivamente tratado sendo, apenas, recolhido como um dejeto, o que, longe de produzir um efeito terapêutico, acentua os efeitos da psicose na qual o sujeito se identifica como puro objeto do gozo do Outro.

Para finalizar, trazemos um episódio em que ele, de forma poética, sintetizou tudo o que discutimos aqui. Denis estava numa sala do Centro, onde fica o mapa-múndi, do qual, como dissemos acima, ele gostava muito e sobre o qual costumava realizar várias viagens delirantes. Denis o olhava muito concentrado como sempre fazia. Uma terapeuta dele se aproximou e lhe disse: "E aí Denis, está viajando, não é?" Ao que ele the respondeu: "Não... viajando não, eu estou só sonhando".

\section{REFERÊNCIAS}

FOUCAULT, M. História da Loucura. São Paulo: Perspectiva, 1993.

FREUD, S. O. Caso de Schreber, artigos sobre técnica e outros trabalhos. In: . Edição standard brasileira das obras psicológicas completas de Sigmund

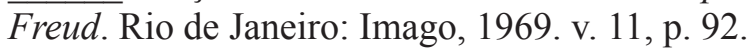

El delírio y los sueños en la "Gradiva" de W. Jensen In: Obras completas. Buenos Aires: Amorrortu, 1986. p. 67.

GOLDBERG, J. A clínica da psicose. Rio de Janeiro: Te Corá: Instituto Franco Basaglia, 1996.

LACAN, J. O Eu na teoria de Freud e na técnica da Psicanálise. In: . $O$ seminário: livro 2. Rio de Janeiro: J. Zahar, 1986.

. O seminário: livro 3: as psicoses. Rio de Janeiro: J. Zahar, 1981.

SARACENO, B. Reabilitação psicossocial: uma prática à espera de teoria. In: PITTA, A. (Org.). Reabilitação psicossocial no Brasil. São Paulo: Hucitec, 1996. 
SOUZA, N. S. A psicose: um estudo lacaniano. 2. ed. rev. e aum. Rio de Janeiro: Revinter, 1999.

Tornar-se negro: as vicissitudes da identidade do negro brasileiro em ascensão social. Rio de Janeiro: Graal, 1983.

Recebido em: fevereiro/2005

Aceito em: setembro/2006 
